\title{
Considering observed and future nonstationarities in statistical downscaling of Mediterranean precipitation
}

\author{
Elke Hertig • Jucundus Jacobeit
}

\begin{abstract}
Winter precipitation in the Mediterranean area for the twenty-first century was statistically downscaled under the explicit consideration of nonstationarities. Nonstationarities arise from substantial modifications of the atmospheric circulation, which lead to significant changes of regional precipitation characteristics. For the detection of nonstationarities in the relationships of the large-scale circulation and regional precipitation in the observational period, statistical model performance under potentially nonstationary conditions was compared to model performance under stationarity. To account for nonstationarity in the future projections, circulation characteristics in general circulation model (GCM) output used to downscale precipitation were also analysed. The correspondence of GCM and observed circulation characteristics was used to specifically select appropriate downscaling models. Statistical model performance was affected by nonstationarities, which was most pronounced not only in the north-eastern Mediterranean regions but also in western Mediterranean North Africa. Furthermore, it was found that variability in the GCM data used for the projections is at least as large as seen in the observational period. This finding underlines the need to explicitly take nonstationarities in statistical downscaling into account. As downscaling result we obtain mainly a reduction of the probability of rain and a rather indifferent pattern regarding the change of the $75 \%$ up to the $95 \%$ quantiles for most regions of the Mediterranean area until the end of the twenty-first century were mainly obtained. However, due to the nonstationarities, results depend strongly on the specific time periods under consideration.
\end{abstract}

E. Hertig $(\bowtie) \cdot$ J. Jacobeit Institute of Geography, University of Augsburg, Alter Postweg 118, 86159 Augsburg, Germany

e-mail: elke.hertig@geo.uni-augsburg.de

\section{Introduction}

Research on precipitation is of special importance, as it is a vital variable in the water budget. Owing to the typical climatic conditions in the Mediterranean area with a high intraand interannual variability of precipitation in combination with social and ecological pressures on water resources (Iglesias et al. 2007), winter precipitation is a key factor of the water budget in the Mediterranean area.

In the context of the water resources management in the Mediterranean area, it is of utmost importance to consider changes of precipitation under the constraints of future climate change. General circulation models (GCMs; e.g. Giorgi and Lionello 2008), regional climate models (RCMs; e.g. Gao et al. 2006), as well as statistical downscaling results (e.g. Hertig and Jacobeit 2008; Hertig et al. 2013a) based on Coupled Model Intercomparison Project round 3 (CMIP3, Meehl et al. 2007) model data project decreased precipitation over the southern and eastern parts of the Mediterranean area, whereas the western and northern parts might experience precipitation increases in winter until the end of the twentyfirst century. Recent Intergovernmental Panel on Climate Change, Assessment Report 5 (IPCC AR5) results indicate that precipitation increases in winter might only occur at the northern edge of the Mediterranean area (Christensen et al. 2013). Concerning the change of precipitation extremes, model projections are less conclusive. As an overall tendency, GCM (Tebaldi et al. 2006; Goubanova and Li 2007) and RCM projections (Beniston et al. 2007; Kyselý et al. 2012; Jacob et al. 2014) point to increases of extreme winter precipitation. Statistical downscaling results also indicate distinct increases of extreme precipitation in winter for many parts of the Mediterranean area (Hertig et al. 2013b). However, results strongly depend on the model used, the type of precipitation extreme (i.e. short-duration extremes up to multiday extremes) and the region considered. 
Over the North Atlantic-European domain, the varying states of the atmospheric circulation can be classified into a few recurrent patterns, so-called weather regimes (e.g. Vautard 1990; Michelangeli et al. 1995; Hertig and Jacobeit 2014). The regimes are associated with specific spatial patterns of precipitation over the Mediterranean area. In winter, the positive (negative) North Atlantic Oscillation (NAO) phase is connected with below- (above-) normal precipitation over southern Europe as well as Northwest Africa (Wanner et al. 2001; Hurrell et al. 2003). Thus, López-Moreno et al. (2011) identified statistically significant negative correlations of the NAO with large parts of the mountain areas over Morocco and Tunisia, the Iberian Peninsula, south-eastern France, Italy, the Balkan Peninsula and central and northern Turkey. However, positive correlations were found for the coastal areas of Egypt and Libya. Donat et al. (2014) derived from an analysis of climate extremes in the Arab region a stronger effect of the $\mathrm{NAO}$ on extremes in the western part (mainly west of Africa and the Mediterranean coastline) compared to the eastern part of the Arab region. Furthermore, the relationship with climate extremes is particularly strong for the negative NAO phase and largely nonsignificant for positive NAO seasons (Donat et al. 2014). Tramblay et al. (2013) identified an influence of the NAO over the Maghreb countries for the precipitation totals and the wet-day frequency, whereas heavy rainfall was found to be only moderately correlated with the NAO. With the Atlantic ridge regime, fewer wet days than average occur over Mediterranean France (Plaut and Simonnet 2001), whereas precipitation is increased over the north-eastern Mediterranean area (Ullmann et al. 2014). With the Blocking regime, there is a sharp increase of the wet-day frequency and heavy precipitation amounts around the French/Spanish border and the French Mediterranean coastal area, an area which is especially exposed to Mediterranean easterlies favouring intense precipitation (Plaut and Simonnet 2001).

Changes in the weather regime characteristics, like variations concerning their phase, location and strength, have an important impact on the winter precipitation variability over the Mediterranean region. For example, the NAO was predominantly in its positive phase between the 1970s and early 1990s, causing precipitation decreases in many parts of the Mediterranean area (Quadrelli et al. 2001; Jacobeit et al. 2007). Temporal variations in the correlations between the NAO index and precipitation can also be explained to some extent by changing longitudinal positions of the NAO centres of action. Moore et al. (2013) found that the centres were displaced to the north-east in the period 1930-1950 and in the period after the 1980s, whereas in 1950-1970, the centres were displaced towards the south-west. Beranová and Huth (2008) identified that during the period of a high NAO index (1986-1998) compared to the period of a low NAO index (1958-1970), the centres of action were shifted eastward. This eastward shift of the southern centre of the NAO caused an enhanced anticyclonicity over the Mediterranean area, drifting the correlations of the NAO index with precipitation towards stronger negative values (Beranová and Huth 2008). Beyond changing positions of the centres of action, teleconnection analysis points to the existence of multiple locations for the two centres of action associated with the NAO, with the dominance of one centre over another changing with time (Moore et al. 2013). Raible et al. (2014) identified the period 1940-1969 as the most anomalous period of the past 130 years with the NAO centres of action shifted to the west and a new wave-train-like teleconnection pattern connecting the British Islands with West Greenland and the eastern Mediterranean. Besides nonstationarities of circulation-climate relationships due to physical variations of the circulation, 'within type' variations (Barry et al. 1981; Beck et al. 2007) can be important. Hertig and Jacobeit (2013) showed that nonstationarities occur within the relationships of precipitation with circulation patterns and their within-type characteristics. The within-type dynamic and thermodynamic variations considerably impacted the results of cross-validation in the framework of statistical downscaling model development.

Since winter precipitation anomalies in the Mediterranean area strongly depend on the large-scale atmospheric circulation, a major question is related to the future evolution of the weather regimes over the North Atlantic-European domain. An increase of the greenhouse gas forcing may change the intensity and geographical patterns of the weather regimes' influence on climate. López-Moreno et al. (2011) concluded that CMIP3 GCMs accurately reproduce the NAO variability and the observed correlations between the NAO and precipitation across the Mediterranean basin. Analyses of Coupled Model Intercomparison Project round 5 (CMIP5) models by Cattiaux et al. (2013) yielded a systematic underestimation of the frequency of occurrence of the winter-blocking episodes and an overestimation of patterns related to zonal variability, e.g. the NAO. Raible et al. (2014) determined a strong variability of the NAO pattern over time, but no difference in the variability between transient model simulations with timevarying external forcing and control simulations with internal climate variability alone. Hertig and Jacobeit (2014) found that in general, the variability of the weather regimes within the considered CMIP5 GCM data sets is comparable to the spread seen in the reanalysis. However, a substantial temporal variability of the regime anomalies in all data sets became apparent and considerably reduced consistency of the NAO regime in the GCM simulations which is not evident in the reanalysis data. Ullmann et al. (2014) assessed for the NAO regime under RCP8.5 scenario conditions a clear eastward extension of the North Atlantic low-pressure system. In addition, the authors found (under scenario conditions) an eastward extension of the Azores High towards the Mediterranean area in the $\mathrm{NAO}+$ regime and a strengthening 
of high pressure around the Azores and low pressure over Iceland in the Atlantic ridge regime. Concerning precipitation in the Mediterranean area, changes of the NAO regime favour rainfall of the north-western Mediterranean area, whereas changes of the Atlantic ridge regime lead to rainfall modifications in the north-eastern Mediterranean area (Ullmann et al. 2014).

Obviously, the variability of the large-scale circulation has an important impact on Mediterranean winter precipitation and has to be taken into account in climate change studies. There is a clear need to incorporate the potentially nonstationary behaviour in the relationships of the atmospheric circulation with regional climate in order to enhance confidence in statistical downscaling results. For the detection of nonstationarities, Hertig and Jacobeit (2013) used bootstrap confidence intervals of the statistical model error of running 31-year periods. In the present study, we regard deviations of the statistical model performance in a potentially nonstationary running calibration framework from the performance under stationarity using cross-validation based on random sampling. Changes of winter (December-February) precipitation in the Mediterranean area are modelled under the explicit consideration of nonstationarities in the weather regime-precipitation relationships. A statistical downscaling approach is applied using generalized linear models (GLMs) based on Tweedie exponential dispersion models. The Tweedie distribution is a compound Poisson-gamma distribution and is used to describe the daily precipitation data in the Mediterranean area. Instead of just using the mean of the probability density function predicted from the GLMs, we inferred from the Tweedie distribution the probability of rain as well as various quantiles of precipitation. As predictors, large-scale weather regimes computed from $700-\mathrm{hPa}$ geopotential heights of the North Atlantic-European domain were used. Additionally, to account for within-regime changes, we selected air temperature, specific humidity and zonal wind component, each of the $850-\mathrm{hPa}$ level, for a region covering the Mediterranean area.

In the earlier analysis of Hertig and Jacobeit (2013), stationary and nonstationary statistical models were given equal consideration in the future projections. This led to the application of one statistical model in case of overall stationary model behaviour in the observational period or of a statistical model ensemble in case of nonstationarities. In contrast, in the present contribution, nonstationarities in the GCM runs are particularly taken into account. For this purpose, the atmospheric conditions of the scenario runs are analysed regarding their correspondence with observed predictor characteristics. Then, the statistical model with the highest predictor correspondence is selected to downscale precipitation in a specific period. Thus, nonstationarity of the past as well as nonstationarity of the modelled future is explicitly taken into consideration. Section 2 describes the data and methodology used in this study. Results are given in Section 3. In Section 4, we discuss the main findings and draw some conclusions from them.

\section{Data and methodology}

\subsection{Data}

\subsubsection{Predictand}

High-resolution daily precipitation data for the Mediterranean land areas $\left(27^{\circ} \mathrm{N}-45^{\circ} \mathrm{N}, 10^{\circ} \mathrm{W}-40^{\circ} \mathrm{E}\right)$ were taken from version 8.0 of the E-OBS $0.25^{\circ} \times 0.25^{\circ}$ gridded data set (Haylock et al. 2008). We selected data for the winter season (December 1950 to February 2010). We removed all grid box time series containing more than 12 missing months (months with more than two missing days per month) from further analysis. This mainly affects grid boxes in the area of northern Africa and over central Turkey. In this context, it has to be emphasized that the quality of the data set is generally reduced over northern Africa due to the very poor station coverage over this area (Haylock et al. 2008). The selection procedure resulted in 4,837 grid boxes.

\subsubsection{Predictors}

We selected National Centers for Environmental Prediction (NCEP) reanalysis data (Kalnay et al. 1996; Kistler et al. 2001) for the period 1950-2010. Daily geopotential height fields at the 700-hPa level in the North Atlantic-European area $\left(20^{\circ} \mathrm{N}-70^{\circ} \mathrm{N}, 70^{\circ} \mathrm{W}-50^{\circ} \mathrm{E}\right)$ were obtained on a $2.5^{\circ} \times 2.5^{\circ}$ horizontal resolution. The 700-hPa fields were used to classify the large-scale circulation into so-called weather regimes (see Section 2.2.3). In addition, we obtained air temperature, specific humidity and zonal wind component of the $850-\mathrm{hPa}$ level for a smaller domain centred over the Mediterranean region $\left(27.5^{\circ} \mathrm{N}-45^{\circ} \mathrm{N}, 10^{\circ} \mathrm{W}-40^{\circ} \mathrm{E}\right)$. We use these variables to characterize within-regime conditions. The choice of the specific pressure levels for the different variables is based on earlier analyses from Hertig and Jacobeit (2013), Hertig et al. (2013b) and Hertig and Jacobeit (2008).

Model data were taken from a three-member MPI-ESMLR (Max Planck Institute Earth System Model running on low-resolution grid) ensemble with different initial conditions of each run, from HadGEM2-ES (Hadley Global Environment Model 2-Earth System) and from the first member of a five-member CanESM2 (second-generation Canadian Earth System Model) ensemble also with different initial conditions of each run. Runs with historical RCP4.5 scenario and RCP8.5 scenario (Van Vuuren et al. 2011) conditions performed for the CMIP5 were downloaded from the CMIP5 archive (http://pcmdi9.1lnl.gov/esgf-web-fe/). We 
used the period 1950-2005 of the historical runs (excluding the historical run of HadGEM2-ES since data were only available for the period 1980-2005) and the period 20062100 of the scenario runs (2006-2099 for HadGEM2-ES). The horizontal resolution of the model output data was extrapolated (MPI-ESM-LR, original resolution $1.875^{\circ}$, HadGEM2-ES, $\left.1.875^{\circ} \times 1.25^{\circ}\right)$ and interpolated (CanESM2, original resolution $2.813^{\circ} \times 2.79^{\circ}$ ), respectively, to that of the reanalysis data $\left(2.5^{\circ} \times 2.5^{\circ}\right)$ using ordinary kriging.

\subsection{Methodology}

\subsubsection{Detection of nonstationarities: running subintervals and random sampling}

We applied two different sampling strategies in order to analyse model performance under nonstationary and under stationary conditions. Following the approach of Hertig and Jacobeit (2013), the whole study period 1950-2010 was split into 31-year subperiods, each shifted by 1 year. Thus, observed interannual to decadal variability, trends and potential temporal nonstationarities are preserved in this sampling method. When the end of the whole time series was reached, years from the beginning of the time series were successively included in order to avoid a more frequent inclusion of years located in the middle of the time series. Sixty subintervals are available for the winter season. Hertig and Jacobeit (2013) subsequently used the (non)overlap of bootstrap confidence intervals of the individual and mean model performances to identify (non)stationary model performance. In the present work, 100 random samples of 31-year size were drawn from the period 1950-2010 to assess model performance under stationary conditions. The minimum and maximum skill scores (for details on the skill scores, see Section 2.2.7) from the 100-member random sampling were taken to define the interval of stationary model performance. Consequently, we defined a nonstationarity in the weather regime-precipitation relationships when the skill scores of several 31-year running subperiods are outside the maximum/minimum skill score interval from random sampling. In this regard, only models are evaluated which show a skilful overall model performance, i.e. which have a random sampling minimum skill score greater than zero.

\subsubsection{Precipitation regions}

In order to define the Mediterranean regions of similar precipitation variability ('precipitation regions'), S-mode, Varimax-rotated principal component analysis (PCA, e.g. Preisendorfer 1988) was applied to the daily E-OBS gridded data of the winter season for the period 1950-2010. The determination of the number of PCs to be extracted follows the approach of Philipp et al. (2007). Seventeen PCs with an overall explained variance of $73.1 \%$ were obtained from this PCA. The assignment of a grid box to a specific precipitation region (i.e. to a specific $\mathrm{PC}$ ) is done by considering the maximum loading of the grid box across all the PCs. For each PC, the grid box with the highest absolute loading on the PC was selected to serve as 'PC representative'. Further analyses were conducted with the time series of the 17 grid boxes representing the precipitation regions. The numbering of the PCs in the results section corresponds to the order of extracted PCs.

\subsubsection{Weather regimes}

Weather regimes were obtained by classifying the NCEP daily geopotential height fields in the North Atlantic-European area for each of the 60 running subintervals and for each of the 100 random samples following the approach described in Hertig and Jacobeit (2014). As a first step, we performed PCAs of the daily winter data, in order to reduce dimensions of the data. Clustering results may be sensitive to the number of PCs kept. Thus, we considered all solutions from five to 15 PCs, capturing between 55 and $90 \%$ of the total variance. The corresponding PC time coefficients of each solution were submitted to the hierarchical clustering method of Ward (Ward 1963; Cheng and Wallace 1993) using the resulting clusters as 'seeds' for optimising $k$-means algorithm (Michelangeli et al. 1995). Four clusters (regimes) were retained according to earlier publications (Michelangeli et al. 1995; Yiou and Nogaj 2004): NAO+ (the positive phase of the North Atlantic Oscillation), blocking, Atlantic ridge and NAO(the negative phase of the North Atlantic Oscillation). Further details on the calculation of the weather regimes and a discussion on their variability in the observational past and in the historical and future GCM model runs can be found in Hertig and Jacobeit (2014). In the present study, we used the assignment of the cases (days) to the clusters to generate weather regime-dependent time series. Subsequent downscaling models were established for each time series separately.

\subsubsection{Principal component analysis of further predictor fields}

In order to describe within-regime characteristics, S-mode, Varimax-rotated PCA was also applied separately to the fields of air temperature, specific humidity and zonal wind component. Depending on the particular 31-year period considered, 6 to 7 PCs with overall explained variances (EVs) of 86-90\% were obtained for the $850-\mathrm{hPa}$ temperature, 10-11 PCs (EV $70-73 \%$ ) for the $850-\mathrm{hPa}$ specific humidity and 7-10 PCs (EV 83-90 \%) for the 850-hPa zonal wind component. The PC scores of these additional variables were also regarded as potential predictors in the downscaling models. 


\subsubsection{Generalized linear models based on Tweedie distributions}

For deriving relationships of the weather regimes with regional precipitation in the Mediterranean area, GLMs (e.g. McCullagh and Nelder 1989) were applied. A maximum likelihood estimation is used to estimate model parameters for the expectation value $E(\cdot)$ for a variable $Y_{t}$ at any given time $t$ :

$E\left(Y_{t}\right)=\mu_{t}=g^{-1}\left(\eta_{t}\right)=g^{-1} \sum_{1}^{i} \chi_{t j} \beta_{j}$

Here, $\eta_{t}$ is a linear predictor (i.e. a linear combination of the explanatory variables), $\mu_{t}$ is the mean for the probability density function at time $t, g$ is the canonical link function, $i$ is the total number of covariates, $\chi_{t j}$ is the value of the $j$ th covariate for observation $t$ and $\beta_{j}$ is parameters whose values have to be estimated from the data.

We used GLMs based on Tweedie exponential dispersion models (EDMs) (Dunn 2004). The Tweedie family of distributions includes Poisson-gamma distributions. This allows for the simultaneous modelling of the discrete and continuous features of precipitation. The probability function of an EDM is of the following form:

$f(y ; \mu, \varphi)=a(y, \varphi) \exp \left[\frac{1}{\varphi}\{y \theta-k(\theta)\}\right]$

where $\mu$ is the mean of the distribution and $\varphi>0$ and the functions $\theta$ and $k(\theta)$ are known functions (Hasan and Dunn 2011; 2012). A special case of EDMs is the three-parameter Tweedie distribution with $\mu$ (the mean), $\varphi>0$ (the dispersion parameter) and $p$ (the Tweedie index parameter). The variance of the distribution is $\operatorname{var}[Y]=\varphi \mu^{p}$. The index $p$ specifies the particular distribution; special cases include the normal $(p=0)$, Poisson $(p=1)$ and gamma $(p=2)$ distributions. For $1<p<2$, the Tweedie family is suitable for modelling positive continuous data with exact zeros (Hasan and Dunn 2011). Estimation of the index parameter $p$ requires sophisticated numerical techniques and was done using a profile maximum likelihood estimate provided in the tweedie package in $\mathrm{R}$ (Dunn 2008). The index parameter $p$ was estimated for four subsamples of each of the 17 regional precipitation time series. The four subsamples were generated according to the days belonging to a specific weather regime in the period 1950-2010. Consequently, $68(4 \times 17)$ estimates of $p$ were calculated. The quality of the fitted distributions was assessed by using quantile residuals (Dunn 2004). From the Tweedy quantile function, we inferred the $75,90,95$ and $99 \%$ quantiles of precipitation. The Tweedie distribution parameters $(\mu, \phi, p)$ can be reparameterized to the Poisson parameter $\lambda$ and the gamma scale and shape parameters $\gamma$ and $\alpha$, when $1<$ $p<2$. Thus, the mean number of rainfall events can be calculated, according to Hasan and Dunn (2012), as:

$\lambda=\frac{\mu^{2-p}}{\varphi(2-p)}$

The probability of rainfall is as follows:

$\pi=1-\exp (-\lambda)$

\subsubsection{Downscaling set-up}

GLMs using Tweedie EDMs as response functions were fitted to the four weather regime-dependent subsamples of the representative grid boxes of the 17 precipitation regions for all 60 running subintervals and for all 100 random samples. In the first step, stationary GLMs without covariates were fitted. This was done to obtain a reference for the calculation of the performance measures (see Section 2.2.7). In the next step, GLMs were fitted using the PCs of $700-\mathrm{hPa}$ geopotential heights underlying the weather regimes, as well as $850-\mathrm{hPa}$ temperature, $850-\mathrm{hPa}$ humidity and $850-\mathrm{hPa}$ wind as covariates describing within-regime characteristics. We applied this methodology to each 31-year period and subsequently predicted precipitation in each 29-year period independent from calibration in order to analyse model performance in a cross-validation framework. Thus, crossvalidation involved partitioning of the whole time period (60 years, December 1950 to February 2010) into subsets. The GLMs were fitted on one subset (calibration, 31 years) and validated on the other subset (validation, 29 years). Multiple rounds of cross-validation were performed using the running subintervals and the random samples, respectively.

\subsubsection{Validation of the downscaling models}

For the validation of the probability of rainfall, the Brier score (BS, Brier 1950) is used. It is essentially the mean squared error of the probability forecasts, considering that the observation $o$ at time $t$ is $o_{t}=1$ if the event occurs and $o_{t}=0$ if the event does not occur. The score averages the squared differences between pairs of model/reference probabilities and the subsequent binary observations (Wilks 2006). Accordingly, the Brier skill score (BSS) is as follows:

$\mathrm{BSS}=1-\frac{\mathrm{BS}_{\text {model }}}{\mathrm{BS}_{\text {reference }}}$

The quantile score (QS, Friederichs and Thorarinsdottir 2012) can be used for the quantile estimates with $y$. Let $F_{1}$, $\ldots, F_{n}$ denotes the respective predictive distributions for the observations $y_{1}, \ldots, y_{n}$ and $\tau$ the quantile of interest. The quantile score is then

$\mathrm{QS}_{\tau}(F, y)=\rho_{\tau}\left(y-F_{(\tau)}^{-1}\right)$ 
with $\rho_{\tau}$ denoting the so-called check function:

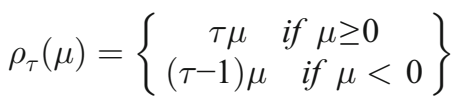

The quantile skill score (QSS) is as follows:

$\mathrm{QSS}=1-\frac{\mathrm{QS}_{\text {model }}}{\mathrm{QS}_{\text {reference }}}$

A zero skill score represents no gain in predictive skill, whereas a perfect model would have a skill score of $100 \%$. The reference for the calculation of the scores is the fitted Tweedie model without covariates. We calculated the skill scores for each weather regime-dependent subsample of a specific precipitation time series. This was done for each of the 60 running subsamples and 100 random samples.

\subsubsection{Projections for the twenty-first century}

The historical model period $1950-2005$ as well as the RCP scenario period 2006-2100 were also split into running 31year subperiods each shifted by 1 year. We computed the regimes as described in Section 2.2.3 for each of the 31-year subperiods. The weather regimes derived from the model data were correlated with the weather regime anomalies of all running 31-year periods of NCEP. For each 31-year model, period precipitation was downscaled using the GLM equation which suits best, i.e. using the corresponding statistical model from the 31-year NCEP period having the highest correlation coefficient. Thus, for the projection of precipitation in each 31-year model period, the GLM equation of that observational period with the strongest resemblance of the regime characteristics was applied. The within-regime characteristics, represented by the centres of variation of 850 -hPa air temperature, specific humidity and zonal wind component (Section 2.2.4), were obtained in the model periods by projecting the model data onto the existing PCs of the observational periods to obtain new predictor time series (for a detailed description of this approach, see, e.g. von Storch and Zwiers 1999). Projections for the twenty-first century were done for each of the 17 precipitation regions.

\section{Results}

\subsection{Precipitation regions and weather regimes}

Precipitation regions derived from S-mode PCA of daily precipitation in the Mediterranean area are displayed in Fig. 1. The assignment of a grid box to a specific precipitation region (i.e. to a specific $\mathrm{PC}$ ) was done by considering the maximum loading of the grid box across all the PCs. The maximum loadings of the grid boxes range from 0.3 to 0.97 . For each PC, the grid box with the highest absolute loading on the PC was selected to serve as 'PC representative'. The highest absolute loadings range from 0.79 to 0.97 . All subsequent analyses were performed for the time series of the representative grid box of a particular region.

Figure 2 displays the four weather regimes of the North Atlantic-European domain, obtained by classifying the NCEP reanalysis daily winter $700-\mathrm{hPa}$ geopotential heights in the period 1950-2010. For each regime, the geopotential composite patterns and the regime anomalies are shown. Composites were derived by calculating the mean $700-\mathrm{hPa}-$ geopotentia height field from all the days belonging to a specific regime. Anomalies were calculated as the deviations of the standardized composite pattern from the standardized long-term mean geopotential height field of all days in the time period considered. The weather regimes are denoted according to Yiou and Nogaj (2004): NAO+ (the positive phase of the North Atlantic Oscillation, zonal pattern of Vautard 1990), blocking, Atlantic ridge and NAO- (the negative phase of the North Atlantic Oscillation, Greenland Anticyclone of Vautard 1990). Further details on the weather regimes can be found in Hertig and Jacobeit (2014).

\subsection{Statistical model performance and detection of nonstationarities}

The mean-variance relationship defined by the Tweedie index parameter $p$ has been determined in order to define the appropriate Tweedie distribution for each of the four weather regime-dependent subtime series of each of the 17 precipitation regions. Values of $p$ range between 1.3 and 1.6, depending on the particular time series. Quantile residuals were used to assess how well the distributions fit the original data (Hasan and Dunn 2011). It was found that the Tweedie distributions fit the daily precipitation data in the Mediterranean area well. As an example, QQ plots for each weather regime-dependent time series of precipitation region 1 (Iberian Peninsula) are shown in Fig. 3.

Comparing the values for the reference Tweedie model fitted to the data without covariates and for the statistically modelled values using the weather regimes and their withinregime characteristics as predictors yields the result that in most $(87 \%)$ of the predictors-based models, the probability of rain is slightly overestimated (Table 1), a feature also seen for the $75 \%$ percentile. In contrast, the higher $90,95 \%$ (Table 2) and $99 \%$ percentiles are generally underestimated, with underestimation of rainfall amounts getting stronger the higher the percentile.

Noticeable differences in the probability of rain (Table 1) and in the $95 \%$ quantile rainfall amounts (Table 2) occur depending on the weather regime and the specific Mediterranean region considered. For instance, the probability 
Fig. 1 Regions of similar precipitation variability ('precipitation regions') derived from S-mode PCA of daily precipitation in the Mediterranean area $\left(27^{\circ} \mathrm{N}-45^{\circ} \mathrm{N}, 10^{\circ} \mathrm{W}-40^{\circ} \mathrm{E}\right)$ for winter (December 1950 to February 2010). The numbers correspond to the PCs. Data: E-OBS v8.0 (Haylock et al. 2008)

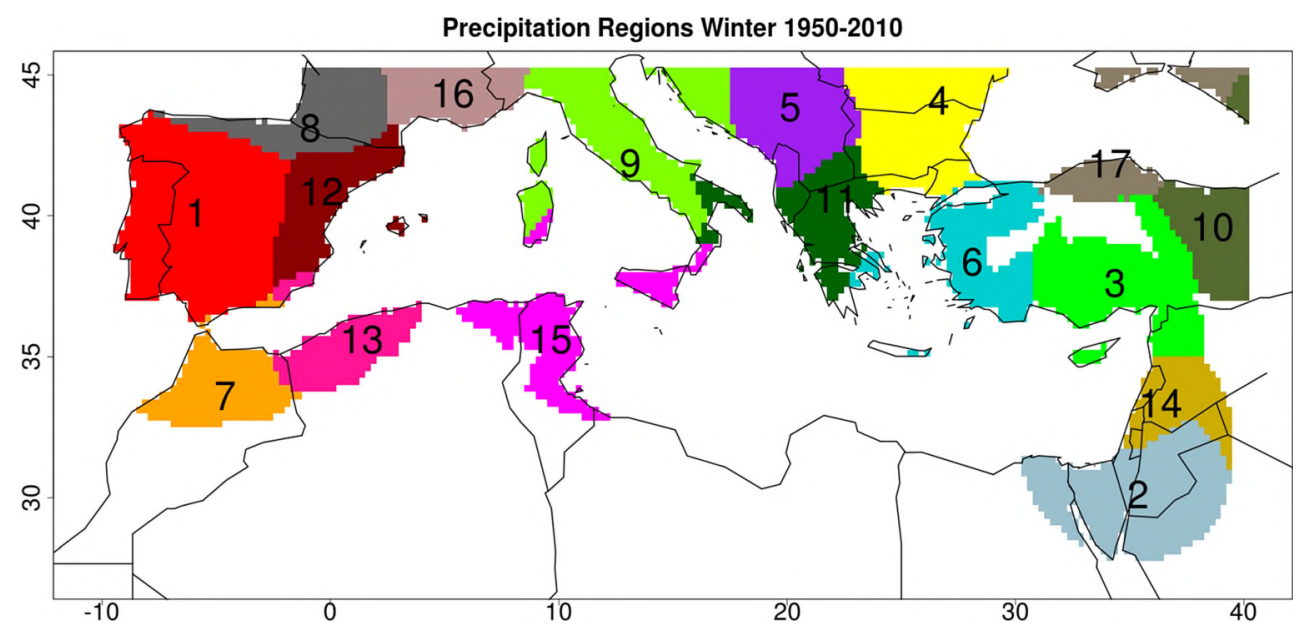

of rain under the occurrence of the blocking regime is particularly high in the north-eastern Mediterranean area (precipitation region 6) due to moist south-western flow, but low for the eastern parts of the Iberian Peninsula (region 12), because of a north-westerly flow component. The Atlantic ridge regime causes below-average probabilities and amounts of rain in the central-northern and north-eastern Mediterranean area (regions 9 and 4) associated with anticyclonic northerly flow, whereas for the easternmost part of the study region (region $10)$, above-average values occur under preferred cyclonic conditions. Under the negative phase of the NAO, high probabilities of rain and high rainfall amounts occur widespread in the Mediterranean area. Anomalous rainfall occurrence and amounts associated with this regime are particularly pronounced for parts of the western Mediterranean area. For positive NAO days, the probability of rain is mostly reduced, whereas the $95 \%$ quantile takes comparable values with those from NAO-days.

Model performance is assessed in terms of the QSS. The mean QSS for the $95 \%$ quantile over the 60 validation sets is tabulated in Table 2. The QSS mostly lies in the range between 20 and $40 \%$ with the exception of precipitation region 2 . For this region, we could not establish skilful statistical models, which might be due to problems with the underlying precipitation data. Apart from this, lower scores and/or larger model spreads for the $99 \%$ quantiles became evident in many cases. An example of the weather regime-dependent QSS is mapped as box-and-whisker plots in Fig. 4, showing the results for the $75,90,95$ and $99 \%$ quantiles of random sampling (grey boxes) and of the running subintervals (green boxes) for
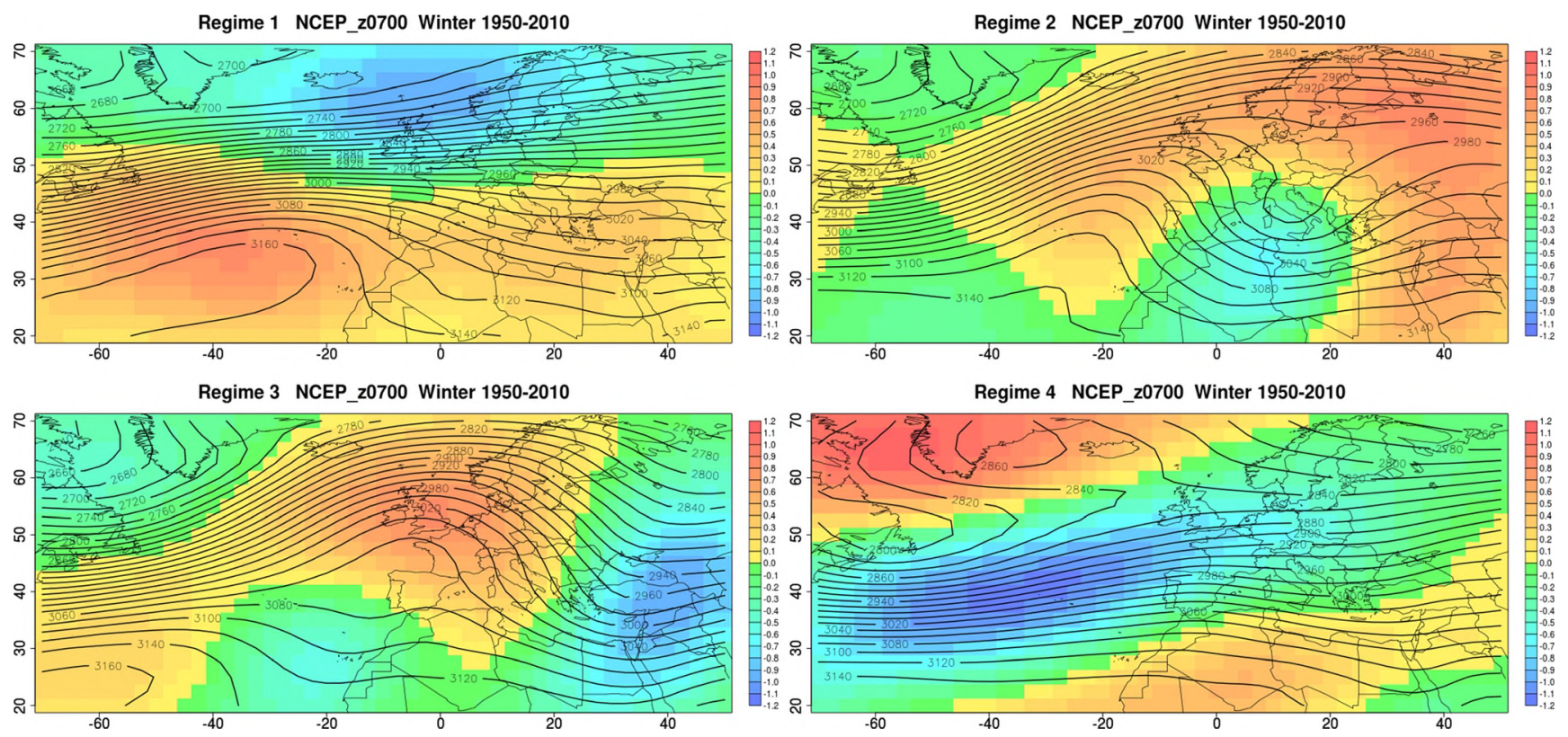

Fig. 2 Weather regimes over the North Atlantic-European area, estimated from the 700-hPa daily winter (DJF) geopotential heights of the NCEP reanalysis. Colours indicate regime anomalies; contour lines,

geopotential height composite pattern for each regime. Regime 1 $\mathrm{NAO}+$, Regime 2 blocking, Regime 3 Atlantic ridge, Regime 4 NAO- 

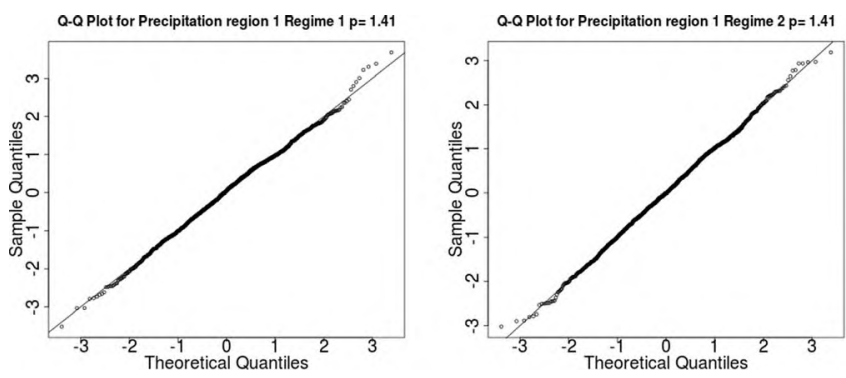

Fig. 3 Example of QQ plots of the quantile residuals after fitting a Tweedie distribution to each weather regime-specific daily precipitation time series of precipitation region 1 . The maximum likelihood estimates

precipitation region 3 (parts of Turkey, Syria and Cyprus). The Tweedie distribution used to describe precipitation is a compound Poisson-gamma distribution. For the bulk part of up to the $95 \%$ quantile, the Tweedie distribution is an appropriate choice, but for the $99 \%$ quantile, a larger model spread can be seen. Thus, for the explicit consideration of very extreme precipitation beyond the $99 \%$ quantile, an extreme value distribution, e.g. a generalized Pareto distribution, would be required.

The BSS is used to assess model performance regarding the probability of rain. The mean BSS over the 60 validation sets for each precipitation region and weather regime can be found in Table 1. In order to detect possible nonstationarities, the variations of the model performance in the 60 running subintervals are set in relation to the range of the model performance resulting from random sampling. Note that only skilful models are evaluated, i.e. models which show a minimum random sampling skill score greater than zero. Thus, all four models for precipitation region 2, the time series of precipitation region 4 associated with the Atlantic ridge regime and the time series related to the $\mathrm{NAO}+$ regime of region 12 are excluded. Figure 5 shows the BSS of each running subinterval and the maximum and minimum BSS resulting from random sampling for the example of precipitation region 7 (Mediterranean Morocco).

Considerable variations of the BSS in the different running subintervals become evident for most of the weather regimedependent precipitation models. However, for the majority of models, the spread of the BSS of the running subintervals lies in the range of the maximum and minimum BSS from random sampling. Yet, for some models, we found distinct departures of the running subinterval BSS to values outside the interval of stationary model performance (see, e.g. regimes 2 and 3 in Fig. 5). Precipitation regions most affected by nonstationary models are located over the north-eastern Mediterranean area, in particular over Turkey (precipitation regions 6 and 10) as well as over the western parts of Mediterranean North Africa (precipitation regions 7,13 and 15). The areas show nonstationarities associated with the Blocking regime and the Atlantic ridge regime. The nonstationarities focus on models calibrated in 31-year subintervals starting in the
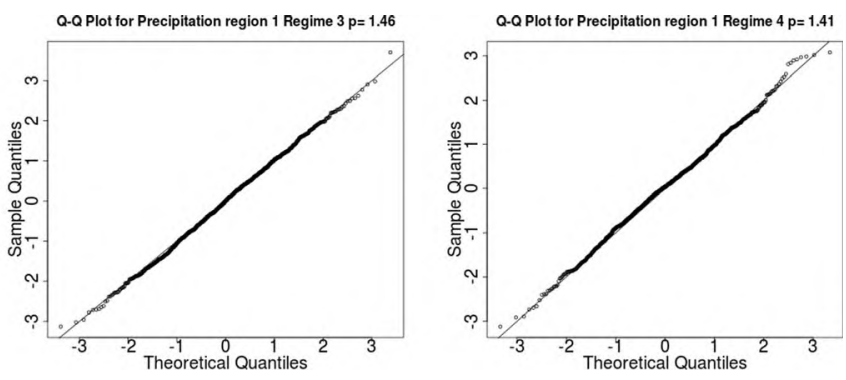

of the Tweedie index parameter $p$ are also indicated. Regime $1 \mathrm{NAO}+$, Regime 2 blocking, Regime 3 Atlantic ridge, Regime 4 NAO-

1970s to the beginning of the 1980s. This means that models calibrated in 31-year subintervals comprising the 1970s, 1980s and 1990s are not adequate to model precipitation outside this period. It points to substantial modifications of the weather regime-precipitation relationships at the end of the 1970 s/beginning of the 1980s. Over the north-eastern Mediterranean area, notably around Bulgaria (precipitation region 4), Greece (region 11) and around the Black Sea (region 17), further nonstationarities occur. They are associated with the NAO- regime for calibrated models starting around the year 2000, with the Atlantic ridge regime for calibrated models starting at the beginning of the 1980s and with the Blocking regime for calibrated models starting around the year 2000. Raible et al. (2014) identified a more eastern position and an intensification of the centres of action of the NAO during the period 1971-2000 compared to the time period 1871-2008. The centres of action of the teleconnection between the eastern Mediterranean and central Europe show differences in the location and intensity between these two periods as well. Beranová and Huth (2008) also find substantial modifications of North Atlantic circulation variability modes which affect correlations with precipitation over Europe and the Mediterranean area. For instance, they observe that the correlations of the East Atlantic pattern with precipitation over the Iberian Peninsula and Italy decreased from about 1970. A further discussion on observed nonstationarities in the North Atlantic-European area can be found in Hertig E, Beck Ch, Wanner H, Jacobeit J (2014, A review of non-stationarities in climate variability with focus on the Northern Hemisphere, Earth Science Reviews, accepted). Overall, the nonstationary variability of the large-scale circulation has direct consequences to the relationships with associated precipitation and impacts the performance of the statistical downscaling models.

We analysed the QSS of the different quantiles' analogue to the BSS and found the major nonstationarities over western Mediterranean North Africa and the north-eastern Mediterranean area to be present also in the quantile assessments. Additionally to the Blocking and Atlantic ridge regimes, nonstationarities in the $90 \%$ QSS and $95 \%$ QSS occur under the NAO regimes. For large parts of the central-northern 
Table 1 Weather regime-dependent probability of rain in each of the 17 precipitation regions

\begin{tabular}{|c|c|c|c|c|c|}
\hline \multicolumn{2}{|c|}{ No. precip. region } & \multirow{2}{*}{$\frac{\text { Regime } 1(\mathrm{NAO}+)}{0.309}$} & \multirow{2}{*}{$\begin{array}{l}\text { Regime } 2 \text { (Blocking) } \\
0.243\end{array}$} & \multirow{2}{*}{$\begin{array}{l}\text { Regime } 3 \text { (Atl. ridge) } \\
0.208\end{array}$} & \multirow{2}{*}{$\frac{\text { Regime } 4\left(\mathrm{NAO}^{-}\right)}{0.543}$} \\
\hline 1 & Reference & & & & \\
\hline 1 & Model & 0.345 & 0.267 & 0.215 & 0.599 \\
\hline 1 & BSS & 35.48 & 32.90 & 36.33 & 35.92 \\
\hline 2 & Reference & 0.145 & 0.116 & 0.233 & 0.148 \\
\hline 2 & Model & 0.149 & 0.12 & 0.232 & 0.158 \\
\hline 2 & BSS & 7.58 & 4.97 & 10.52 & 11.41 \\
\hline 3 & Reference & 0.293 & 0.308 & 0.362 & 0.34 \\
\hline 3 & Model & 0.317 & 0.332 & 0.399 & 0.378 \\
\hline 3 & BSS & 35.78 & 34.83 & 35.83 & 36.22 \\
\hline 4 & Reference & 0.225 & 0.313 & 0.182 & 0.303 \\
\hline 4 & Model & 0.259 & 0.328 & 0.207 & 0.34 \\
\hline 4 & BSS & 25.60 & 26.36 & 20.30 & 22.66 \\
\hline 5 & Reference & 0.334 & 0.382 & 0.301 & 0.42 \\
\hline 5 & Model & 0.368 & 0.451 & 0.368 & 0.449 \\
\hline 5 & BSS & 26.96 & 24.58 & 27.62 & 26.08 \\
\hline 6 & Reference & 0.379 & 0.459 & 0.32 & 0.422 \\
\hline 6 & Model & 0.421 & 0.485 & 0.364 & 0.412 \\
\hline 6 & BSS & 35.02 & 37.79 & 36.19 & 33.25 \\
\hline 7 & Reference & 0.255 & 0.306 & 0.249 & 0.39 \\
\hline 7 & Model & 0.272 & 0.311 & 0.235 & 0.406 \\
\hline 7 & BSS & 31.53 & 31.42 & 28.45 & 38.62 \\
\hline 8 & Reference & 0.564 & 0.416 & 0.268 & 0.582 \\
\hline 8 & Model & 0.607 & 0.445 & 0.28 & 0.564 \\
\hline 8 & BSS & 32.34 & 31.45 & 29.72 & 24.44 \\
\hline 9 & Reference & 0.334 & 0.366 & 0.179 & 0.426 \\
\hline 9 & Model & 0.368 & 0.409 & 0.203 & 0.447 \\
\hline 9 & BSS & 34.88 & 34.64 & 33.02 & 32.04 \\
\hline 10 & Reference & 0.334 & 0.33 & 0.489 & 0.366 \\
\hline 10 & Model & 0.362 & 0.361 & 0.524 & 0.386 \\
\hline 10 & BSS & 23.71 & 27.44 & 28.82 & 27.77 \\
\hline 11 & Reference & 0.276 & 0.358 & 0.201 & 0.331 \\
\hline 11 & Model & 0.312 & 0.424 & 0.219 & 0.322 \\
\hline 11 & BSS & 34.30 & 32.73 & 29.46 & 29.60 \\
\hline 12 & Reference & 0.167 & 0.177 & 0.149 & 0.285 \\
\hline 12 & Model & 0.205 & 0.204 & 0.163 & 0.302 \\
\hline 12 & BSS & 20.66 & 21.87 & 23.64 & 23.43 \\
\hline 13 & Reference & 0.224 & 0.351 & 0.228 & 0.275 \\
\hline 13 & Model & 0.258 & 0.366 & 0.238 & 0.291 \\
\hline 13 & BSS & 26.87 & 23.59 & 26.96 & 26.82 \\
\hline 14 & Reference & 0.389 & 0.342 & 0.53 & 0.362 \\
\hline 14 & Model & 0.375 & 0.333 & 0.529 & 0.373 \\
\hline 14 & BSS & 23.56 & 25.44 & 25.36 & 30.82 \\
\hline 15 & Reference & 0.29 & 0.375 & 0.263 & 0.264 \\
\hline 15 & Model & 0.336 & 0.428 & 0.299 & 0.293 \\
\hline 15 & BSS & 27.17 & 22.31 & 28.18 & 25.42 \\
\hline 16 & Reference & 0.343 & 0.229 & 0.143 & 0.425 \\
\hline 16 & Model & 0.35 & 0.239 & 0.159 & 0.424 \\
\hline 16 & BSS & 27.20 & 24.88 & 25.22 & 28.13 \\
\hline 17 & Reference & 0.327 & 0.373 & 0.412 & 0.441 \\
\hline
\end{tabular}


Table 1 (continued)

\begin{tabular}{|c|c|c|c|c|c|}
\hline \multicolumn{2}{|c|}{ No. precip. region } & \multirow{2}{*}{$\begin{array}{c}\text { Regime } 1(\mathrm{NAO}+) \\
0.397\end{array}$} & \multirow{2}{*}{$\begin{array}{l}\text { Regime } 2 \text { (Blocking) } \\
0.429\end{array}$} & \multirow{2}{*}{$\begin{array}{l}\text { Regime } 3 \text { (Atl. ridge) } \\
0.483\end{array}$} & \multirow{2}{*}{$\frac{\text { Regime } 4(\mathrm{NAO}-)}{0.493}$} \\
\hline 17 & Model & & & & \\
\hline 17 & BSS & 29.66 & 30.50 & 27.97 & 29.77 \\
\hline
\end{tabular}

Shown is the mean over the 60 running validation periods

Reference Tweedie model fitted to the data without covariates, Model statistically modelled values using the weather regimes and their within-regime characteristics as predictors, BSS Brier skill score

Mediterranean area (region 9) and Greece (region 11), nonstationarities of the QSSs appear under the NAO+ regime for calibrated models starting in the 1970s. Over the eastern Mediterranean area (region 14) and around the Black Sea (region 17), nonstationarities arise under the NAO- regime for calibrated models starting in the 2000s.

\subsection{Analysis of nonstationarities}

In order to study the physical background of the detected nonstationarities, we computed composites of the regime anomalies and the within-regime temperature, humidity and zonal wind conditions for selected time periods. As noted in Section 3.2, major nonstationarities occur over western North Africa and the north-eastern Mediterranean area at the end of the 1970s/beginning of the 1980s. Therefore, we calculated composites for the years 1950-1980 and for the period 1980 2010. Considerable changes between the two periods result for the Atlantic ridge regime (regime 3 in Fig. 2). The ridge is markedly shifted eastwards, expanded and intensified in the later period. The ridge is then directly located over the western Mediterranean area, inducing dryer atmospheric conditions over this area. Consequently, total precipitation associated with this regime is lower, for example over Morocco (region 7) about $1 \mathrm{~mm} /$ day compared to about $4 \mathrm{~mm} /$ day in 1950 1980. However, the probability of rain remains almost unchanged; thus, the low total precipitation values result from low rainfall amounts. Overall, the application of the GLM model calibrated in 1980-2010 to years outside this period leads to a strong underestimation of rainfall. As a result, we see significant departures in the statistical model performance, leading to the nonstationarities observed in the skill scores.

Further nonstationarities were detected for regions of the north-eastern and northern Mediterranean area, in particular connected with the NAO regimes (Section 3.1). For the $\mathrm{NAO}+$ regime and the NAO- regime, specific change points were detected around the beginning of the 1970s and 2000s, respectively. Thus, we calculated composites for the years 2000-2010 and 1950-1969 against the period 1970-2000. The southern negative anomaly centre of the NAO- regime (regime 4 in Fig. 2) is much stronger and more confined to the North Atlantic in the period 1970-2000. In contrast, in the years $2000-2010$ and $1950-1969$, this centre is overall weaker, but much more spread out towards the east, as far as the north-eastern Mediterranean and Black Sea area. In the latter case, considerably strengthened zonal west winds, increased specific humidity and lower atmospheric temperatures occur over the north-eastern Mediterranean area. In these years, the probability of rain and the quantile values are higher in the affected regions, i.e. parts of Greece, Turkey, Bulgaria and Romania (region 4) and further around the Black Sea (region 17). When we apply the regression models associated with these relationships to the period 1970-2000, the probability of rain and the 90,95 and $99 \%$ quantile values are significantly underestimated, leading to the nonstationarities in the model performance.

\subsection{Nonstationarities in the GCM data}

The question arises whether nonstationarities occur in a similar vein in the GCM data used to project regional precipitation change as observed in the reanalysis. We model regional precipitation in the running 31-year model periods under the use of the statistical model best suited for a specific period (see Section 2.2.8). The mean correlation coefficients between the weather regimes derived from the model data with the weather regime anomalies of NCEP range between 0.4 and 0.8 . Looking at the selected statistical models revealed that in the historical GCM runs, weather regimes associated with major nonstationary regime-precipitation relationships prevail in 13 (MPI-ESM-LR) up to 19 (CanESM2) out of 55 subperiods (24-35\%). Under the RCP4.5 scenario conditions, $19 \%$ up to $37 \%$ of the subperiods resemble nonstationary weather regime anomalies, under the RCP8.5 scenario 26-32\%. The models selected in the GCM data did not show a bias towards specific states of the weather regimes, but comprise the whole range of observed variability. Thus, we found variability in the models' weather regime characteristics which is at least as large as seen in the reanalysis.

\subsection{Precipitation projections for the twenty-first century}

Results of the statistical downscaling of daily precipitation in the Mediterranean area under enhanced greenhouse gas conditions in the twenty-first century are shown in Figs. 6 and 7. In Fig. 6, one GCM run (CanESM2) was selected to illustrate 
Table 2 Weather regime-dependent $95 \%$ quantile in each of the 17 precipitation regions

\begin{tabular}{|c|c|c|c|c|c|}
\hline \multicolumn{2}{|c|}{ No. precip. region } & \multirow{2}{*}{$\frac{\text { Regime } 1(\mathrm{NAO}+)}{9.965}$} & \multirow{2}{*}{$\begin{array}{l}\text { Regime } 2 \text { (Blocking) } \\
7.32\end{array}$} & \multirow{2}{*}{$\frac{\text { Regime } 3 \text { (Atl. ridge) }}{6.126}$} & \multirow{2}{*}{$\begin{array}{l}\text { Regime } 4\left(\mathrm{NAO}^{-}\right) \\
15.505\end{array}$} \\
\hline 1 & Reference & & & & \\
\hline 1 & Model & 7.202 & 4.924 & 4.244 & 11.69 \\
\hline 1 & QSS & 27.44 & 34.13 & 36.04 & 29.14 \\
\hline 2 & Reference & 8.863 & 5.896 & 11.95 & 8.078 \\
\hline 2 & Model & 8.629 & 6.825 & 10.779 & 6.733 \\
\hline 2 & QSS & 0.97 & -2.23 & 7.38 & 8.81 \\
\hline 3 & Reference & 15.144 & 15.093 & 17.435 & 16.394 \\
\hline 3 & Model & 10.378 & 10.468 & 12.163 & 11.39 \\
\hline 3 & QSS & 35.71 & 32.68 & 34.59 & 32.87 \\
\hline 4 & Reference & 5.982 & 8.436 & 4.636 & 7.02 \\
\hline 4 & Model & 4.184 & 6.212 & 3.29 & 5.197 \\
\hline 4 & QSS & 29.44 & 25.69 & 26.82 & 23.82 \\
\hline 5 & Reference & 9.295 & 10.229 & 7.947 & 10.798 \\
\hline 5 & Model & 6.997 & 7.635 & 5.772 & 8.556 \\
\hline 5 & QSS & 26.78 & 25.31 & 31.29 & 20.68 \\
\hline 6 & Reference & 17.813 & 19.836 & 15.358 & 17.455 \\
\hline 6 & Model & 12.598 & 14.658 & 10.053 & 13.662 \\
\hline 6 & QSS & 30.63 & 24.74 & 36.08 & 19.59 \\
\hline 7 & Reference & 12.276 & 14.048 & 10.819 & 16.541 \\
\hline 7 & Model & 9.109 & 10.446 & 8.185 & 12.315 \\
\hline 7 & QSS & 15.86 & 15.68 & 15.56 & 18.73 \\
\hline 8 & Reference & 18.697 & 14.948 & 9.382 & 15.236 \\
\hline 8 & Model & 14.749 & 11.875 & 6.672 & 13.246 \\
\hline 8 & QSS & 26.36 & 25.45 & 27.36 & 18.29 \\
\hline 9 & Reference & 12.345 & 13.479 & 7.217 & 13.367 \\
\hline 9 & Model & 8.988 & 9.418 & 4.64 & 10.264 \\
\hline 9 & QSS & 30.00 & 28.17 & 35.13 & 20.55 \\
\hline 10 & Reference & 7.94 & 8.023 & 11.263 & 8.578 \\
\hline 10 & Model & 5.884 & 6.221 & 8.876 & 6.572 \\
\hline 10 & QSS & 27.51 & 19.51 & 18.63 & 18.83 \\
\hline 11 & Reference & 6.956 & 9.528 & 5.096 & 7.65 \\
\hline 11 & Model & 4.574 & 6.447 & 3.347 & 6.071 \\
\hline 11 & QSS & 27.61 & 26.78 & 30.61 & 22.55 \\
\hline 12 & Reference & 5.423 & 7.241 & 6.027 & 7.533 \\
\hline 12 & Model & 4.194 & 5.35 & 4.198 & 5.754 \\
\hline 12 & QSS & 23.82 & 25.77 & 27.60 & 23.05 \\
\hline 13 & Reference & 9.849 & 12.42 & 10.246 & 9.134 \\
\hline 13 & Model & 7.729 & 10.089 & 7.419 & 7.12 \\
\hline 13 & QSS & 22.07 & 17.14 & 21.42 & 17.11 \\
\hline 14 & Reference & 16.939 & 15.049 & 22.308 & 16.426 \\
\hline 14 & Model & 13.965 & 12.046 & 18.495 & 12.195 \\
\hline 14 & QSS & 22.42 & 24.40 & 19.52 & 18.57 \\
\hline 15 & Reference & 10.143 & 11.758 & 9.739 & 7.215 \\
\hline 15 & Model & 8.085 & 9.17 & 7.297 & 5.449 \\
\hline 15 & QSS & 18.44 & 24.71 & 18.34 & 24.55 \\
\hline 16 & Reference & 16.759 & 12.679 & 8.101 & 18.826 \\
\hline 16 & Model & 13.33 & 9.367 & 6.313 & 15.697 \\
\hline 16 & QSS & 26.79 & 30.43 & 31.22 & 20.85 \\
\hline 17 & Reference & 10.71 & 10.468 & 11.919 & 12.536 \\
\hline
\end{tabular}


Table 2 (continued)

\begin{tabular}{lllllc}
\hline No. precip. region & Regime 1 (NAO+) & Regime 2 (Blocking) & Regime 3 (Atl. ridge) & Regime 4 (NAO-) \\
\hline 17 & Model & 7.522 & 7.416 & 8.717 & 9.623 \\
17 & QSS & 30.02 & 22.69 & 23.99 & 16.55 \\
\hline
\end{tabular}

Shown is the mean over the 60 running validation periods

Reference Tweedie model fitted to the data without covariates, Model statistically modelled values using the weather regimes and their within-regime characteristics as predictors, QSS quantile skill score

in detail the assessment results for the probability of rain and the $95 \%$ quantile, exemplary for three precipitation regions, region 1 (Iberian Peninsula), region 3 (parts of Turkey, Syria, Cyprus) and region 7 (Mediterranean Morocco). The plots include the means of the weather regime-dependent values and the means of the values aggregated across all weather regimes for each of the 31-year running subintervals under historical (1950-2005) and under RCP4.5 and RCP8.5 scenario conditions (2006-2100). Note that a chronological interpretation can only be done for the $x$-axis values from 1950 to 1975 in case of the historical runs (area between the grey dashed vertical lines) and from 2006 to 2070 for the scenario runs (area between the black dashed vertical lines), since when the end of a time series was reached, years from the beginning of the time series were successively included. The modelled values exhibit a strong dependence on the particular weather regime. Thus, the probability of rain in precipitation region 1 (Iberian Peninsula) shows particularly high values of about 0.6 under the occurrence of the NAO- regime, whereas low values of about 0.2 occur under the Atlantic ridge regime. The aggregation to the complete time series then yields the averaged value across all weather regimes, in the example of region 1 to a value just under 0.4 .

Furthermore, a high variability between the different 31 year subintervals becomes visible in the weather regimedependent assessment results. For the probability of rain, the variability seen in the RCP4.5 and RCP8.5 scenarios is quite similar to the one seen in the historical period. In contrast, the weather regime-dependent $95 \%$ quantile values show a larger spread for some precipitation regions in the scenario case, e.g. under the Atlantic ridge regime in regions 3 and 14 or under the Blocking regime in region 6 . This characteristic can be seen in Fig. 6 with the example of precipitation region 3. In general, the pronounced variability seen between the different 31-year model periods partly results from the explicit consideration of the specific weather regime characteristics in the statistical downscaling approach. Depending on the characteristics of the atmospheric circulation, the corresponding statistical model was applied, comprising particular relationships between these regime-dependent characteristics of the circulation and regional precipitation developments. The variability between the different 31-year periods is obtained regardless of the strength of the radiative forcing. This can be seen in Fig. 6 in the modelled values beyond the year 2070, since in these subperiods, years from the end as well as from the beginning of the scenario period are included.

Figure 6 shows on the right-hand axis (note the different scale) the change between the scenario period 2069-2099 with respect to the historical period 1969-1999 for the RCP4.5 and the RCP8.5 scenarios. Again, a strong dependence of the values on the weather regimes is obvious. For the aggregated values (large grey to black dots), we mostly see only small to moderate changes in the probability of rain and in the $95 \%$ quantile. An analysis across all precipitation regions yields the strongest changes of the probability of rain and the $95 \%$ quantile for precipitation regions 7 and 15 (Morocco, Tunisia and Sicily, region 15 mainly probability of rain) as well as regions 3, 6 and 17 (Turkey, mainly $95 \%$ quantile) with a reduction of up to about $10 \%$ of the probability of rain and decreases of the $95 \%$ quantile in the order of up to 4 to $5 \mathrm{~mm} /$ day. Decreases are in general stronger under the RCP4.5 scenario than the RCP8.5 scenario, a feature which cannot be explained straightforwardly. Aside, note that attention should be paid to the projected changes presented as time-slice differences, since not necessarily long-term trends are captured, but the actual state of the circulation of the
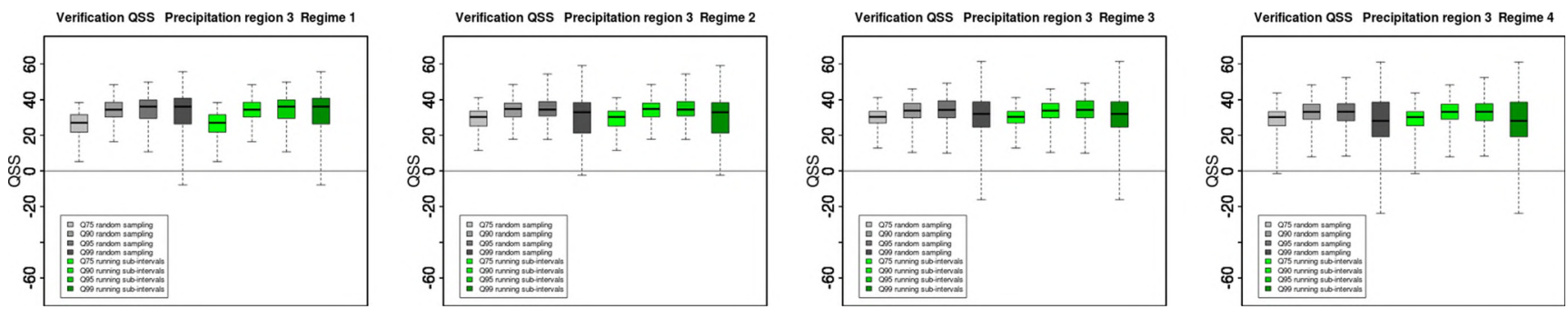

Fig. 4 Quantile skill scores (75, 90, 95 and $99 \%$ ) for the 100 random samples (grey boxes) and for the 60 running subintervals (green boxes) for precipitation region 3 . Note that the whiskers extend to the whole data range 

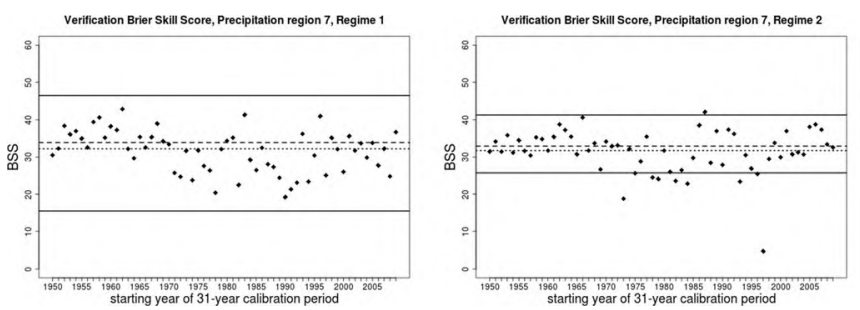

Fig. 5 Brier skill score (verification) for precipitation region 7. BSS is calculated for each of the 60 running subintervals (diamond symbols), differentiated by the four weather regimes. The maximum and minimum
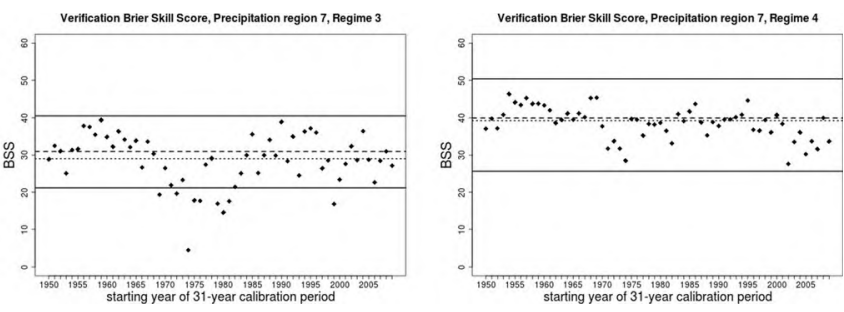

BSS from random sampling (solid lines), the median BSS of the 60 running subintervals (dotted line), and the median BSS from random sampling (dashed line) are also included
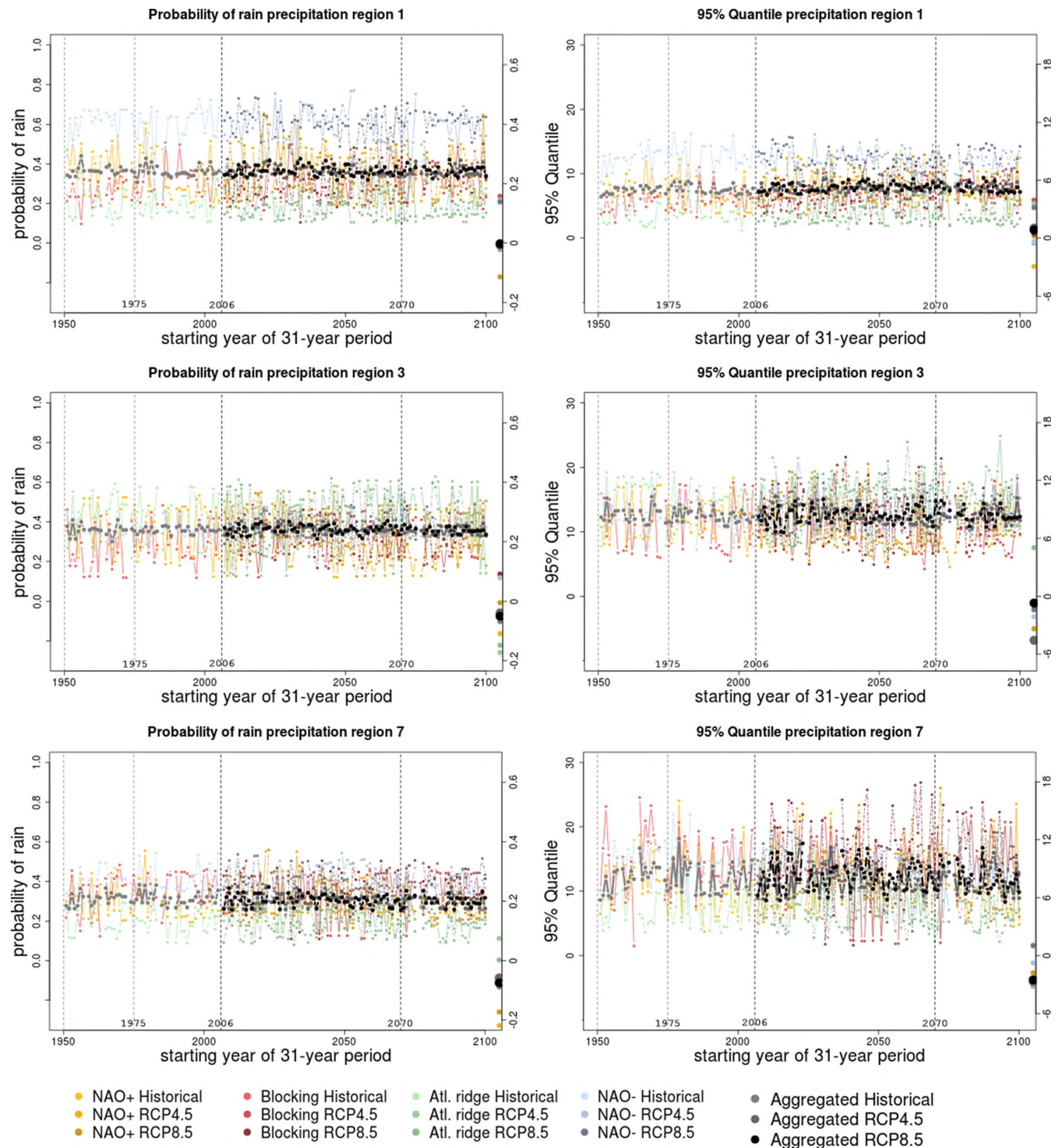

Fig. 6 Statistically modelled probability of rain (left side) and $95 \%$ quantile of daily precipitation (right side) for precipitation regions 1, 3 and 7. Shown are the means of the weather regime-dependent values and of the re-composed overall time series for each of the 31-year running subintervals under historical (1950-2005) and under RCP4.5 and RCP8.5

scenario (2006-2100) conditions for the CanESM2 run. Symbols on the right-hand axis indicate change between the scenario period 2069-2099 with respect to the historical period 1969-1999 for the RCP4.5 and the RCP8.5 scenarios. Note the different scale for the change on the righthand axis. For further details, see text 

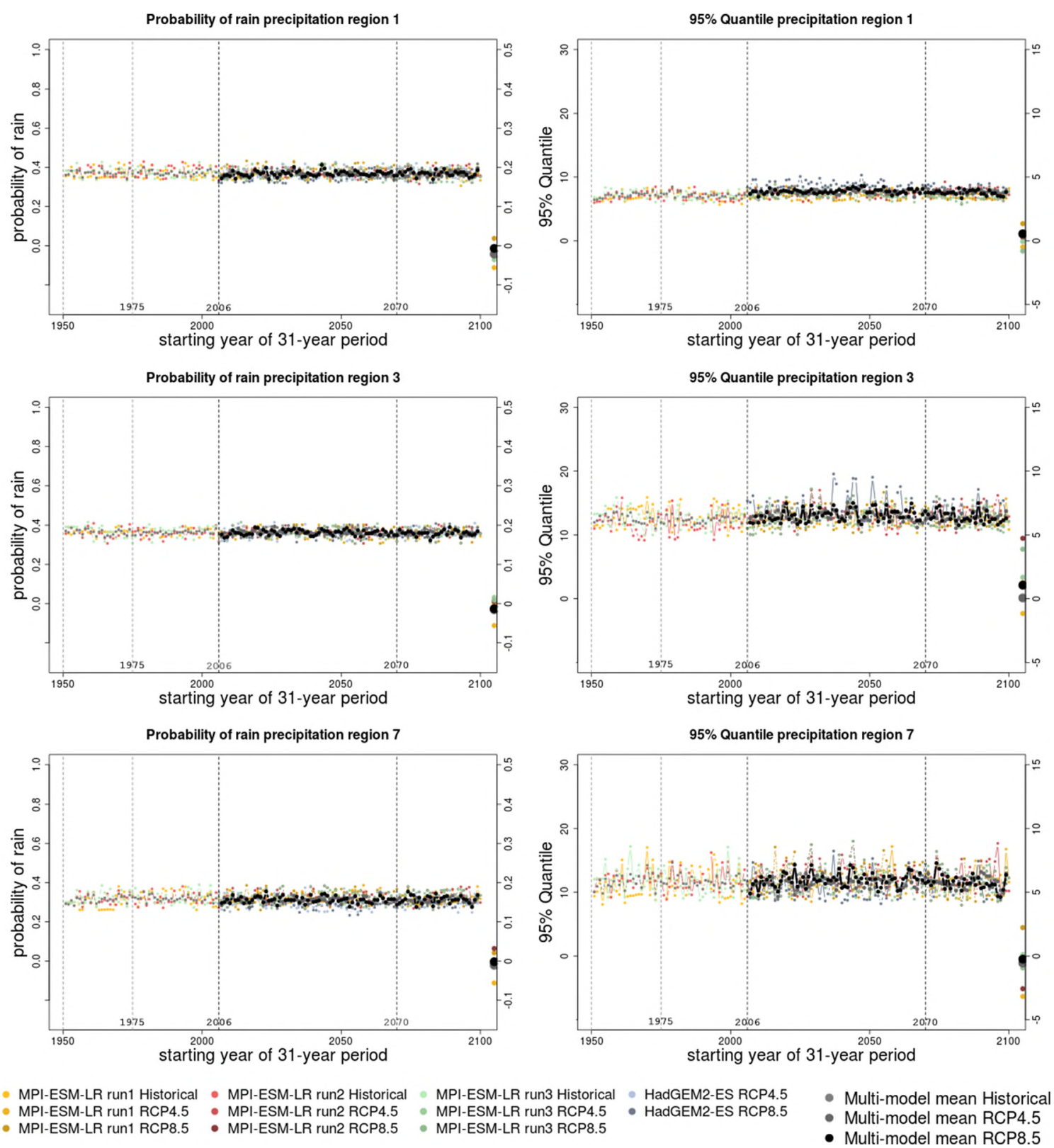

Fig. 7 Statistically modelled probability of rain (left side) and $95 \%$ quantile of daily precipitation (right side) for precipitation regions 1,3 and 7. Shown are the means of the re-composed time series over each of the 31-year running subintervals under historical (1950-2005) and under RCP4.5 and RCP8.5 scenario (2006-2100) conditions for MPI-ESM-LR

selected time slices. For instance, decreases of the $95 \%$ quantile for precipitation region 13 under the RCP 8.5 scenario amount to $-2.2 \mathrm{~mm} /$ day compared to those for the periods 2069-2099 and 1969-1999, but to $-3.5 \mathrm{~mm}$ /day when taking the periods 2066-2096 and 1969-1999 (not shown).

Figure 7 shows the downscaling results for the probability of rain and the $95 \%$ quantile as the 31 -year mean values of the aggregated time series for the other GCM runs (MPI-ESM-LR run1, MPI-ESM-LR run2, MPI-ESM-LR run3 and HadGEM2-ES) were considered as well as the multi-model run1, MPI-ESM-LR run2, MPI-ESM-LR run3 and HadGEM2-ES. Symbols on the right-hand axis indicate change between the scenario period 2069-2099 with respect to the historical period 1969-1999 for the RCP4.5 and the RCP8.5 scenarios. Note the different scale for the change on the right-hand axis. For further details, see text

mean across all models, exemplary for precipitation regions 1 , 3 and 7, again. Note that a chronological interpretation can only be done for the $x$-axis values from 1950 to 1975 in the case of historical runs (area between the grey dashed vertical lines) and from 2006 to 2070 for the scenario runs (area between the black dashed vertical lines). Looking at the change between the periods 2069-2099 and 1969-1999 (symbols on the right-hand axis), a considerable spread of the results can be seen, depending on the scenario, the GCM and the model run used. For example, for the $95 \%$ quantile 
of region 3 , about $-1 \mathrm{~mm} /$ day is modelled under RCP4.5 scenario conditions from MPI-ESM-LR run1, but $+5 \mathrm{~mm} /$ day under the RCP8.5 scenario from MPI-ESM-LR run 2. Summarized across all precipitation regions, the multi-model means show small decreases of up to slight increases (mainly in the RCP8.5 scenario case) of the $95 \%$ quantile. The probability of rain is slightly reduced under the RCP4.5 scenario and shows no change up to small increases under the RCP8.5 scenario for the majority of the precipitation regions.

Results were illustrated for the probability of rain and the $95 \%$ quantile. For the 75 and $90 \%$ quantiles, no clear trends result until the end of the twenty-first century. The $90 \%$ quantile values mostly show a tendency towards higher values in the order of about $1 \mathrm{~mm} /$ day for the multi-model mean under RCP8.5 forcing. For the $99 \%$ quantile, the changes depend on the precipitation region and scenario considered, ranging for the multi-model mean under the RCP8.5 scenario assumptions from an increase of about $3 \mathrm{~mm} /$ day for precipitation region 6 to a decrease of about $1 \mathrm{~mm} /$ day for precipitation region 13. Note, however, that the skill scores for the $99 \%$ quantile are mostly lower and more variable (see Section 3.2), so that results for this extreme quantile should be regarded with caution.

\section{Discussion and conclusions}

The Tweedie family of distributions in the GLM framework was used to statistically downscale weather regime-dependent daily precipitation in the Mediterranean area. The compound Poisson-gamma distribution has been found to be appropriate to model the probability of rain and the bulk part of the precipitation distribution up to the $95 \%$ quantile. However, if the extreme upper tail of the distribution should be of interest, extreme value theory should be taken into consideration.

Nonstationarities in the statistical model performance were analysed by comparing the Brier and quantile skill scores of potentially nonstationary running 31-year subintervals with the scores obtained under stationary conditions, i.e. from random sampling. We found that statistical model performance was affected by nonstationarities, which was most pronounced not only in the north-eastern Mediterranean regions but also in western Mediterranean North Africa.

There is substantial variability of the weather regimes and their within-regime characteristics in the observational period 1950-2010. Remarkable variations in the anomaly intensities as well as spatial shifts of the anomalies are observed. For example, there was an intensification, expansion and eastward shift of high pressure in the Atlantic ridge regime in 19802010 compared to $1950-1980$. This substantially changed the relationship between this weather regime and rainfall in the north-eastern Mediterranean area and western North Africa and led to nonstationarities in the statistical model performance as expressed by the Brier and quantile skill scores. Thus, it is important to consider nonstationarities in the observational period which is used to develop the statistical models. If there is a significant variability in the circulationclimate relationships, and statistical models do not take them into account, they are inadequate tools for regional climate change projections. In this context, it is favourable to have long observational records available in order to capture as much of the circulation variability as possible for model calibration. Furthermore, the presence of nonstationarities in the predictors results in some technical requirements in the context of statistical downscaling model development. Thus, it does not suffice to do simple split sampling and to select only one or two calibration/validation periods, but there is a need to derive more complex models in a cross-validation framework, covering a larger range of the observed variability. Furthermore, there is an issue when considering only one single or a few grid boxes or climate indices such as the NAO index as predictors, since there might be substantial changes in the spatial location of the relevant predictor anomalies.

Circulation variability in the GCMs also plays a crucial role. If the variability in the GCMs resembles that seen in the observations, it strengthens the assumption made within the downscaling context that the relationships found in the observational period can be transferred into the future. In the present study, the model variability was found to be at least as large as seen in the observational period. Variability in the GCMs can even be greater and/or future circulation can actually deviate from the patterns observed in the past. As shown, for example by Hertig and Jacobeit (2014), the NAO- regime specifications are highly varying with time in the GCM historical and scenario runs, and this is not the case in the reanalysis data. This cannot be captured by the present stateof-the-art statistical downscaling approaches. But at least, it is possible to adapt to future variability to a certain degree by analysing which observational relationships are closest to particular future conditions. We addressed this issue by analysing the specific states of the circulation in the model data (comprising both weather regimes as well as withinregime characteristic) and subsequently applied the statistical model from that observational period which most strongly resembles the specific model conditions. An alternative to this approach is the use of statistical model ensembles also within the projections, i.e. to use several (stationary and nonstationary) statistical models in parallel to project future changes, as done for instance by Hertig and Jacobeit (2013).

The statistical projections of Mediterranean precipitation until the end of the twenty-first century under enhanced greenhouse gas conditions show large changes of the individual weather regime-dependent precipitation distributions. 
Aggregated across the weather regimes and averaged to multimodel means, mainly a reduction of the probability of rain and a rather indifferent pattern regarding the change of the $75 \%$ up to the $95 \%$ quantiles of precipitation arise. However, results are strongly connected to the specific time period under consideration. In addition, there is a specific spread of the results, originating from the use of different scenarios, GCMs and model runs, though it is overall less than that arising from the consideration of different weather regimes.

The present study showed that there is a great variability in the circulation of the North Atlantic-European sector and that this variability can cause nonstationarities in the relationships between large-scale circulation and Mediterranean precipitation. Thus, statistical downscaling approaches, which use the relationships between the large-scale circulation and regional/ local climate variables, have to adopt strategies in order to make more realistic projections. Further work remains in this field, like for instance to find approaches as simple and computationally inexpensive as possible to be applicable by the larger climate change community, but powerful enough to adequately incorporate dynamical nonstationarities.

Acknowledgments This project is funded by the German Research Foundation under contract HE 6186/2-1. We acknowledge the E-OBS data set from the EU-FP6 project ENSEMBLES (http://ensembles-eu. metoffice.com), the data providers in the ECA\&D project (http://www. ecad.eu), the climate modelling groups and the World Climate Research Programme's Working Group on Coupled Modelling for making available the CMIP5 data set. Also, we acknowledge the free availability of the NCEP reanalysis data.

\section{References}

Barry RG, Kiladis G, Bradley RS (1981) Synoptic climatology of the Western United States in relation to climatic fluctuations during the twentieth century. J Climatol 1:97-113

Beck C, Jacobeit J, Jones PD (2007) Frequency and within-type variations of large-scale circulation types and their effects on lowfrequency climate variability in Central Europe since 1780. Int J Climatol 27:473-491

Beniston M, Stephenson D, Christensen O, Ferro C, Frei C, Goyette S, Halsnaes K, Holt T, Jylhä K, Koffi B, Palutikof J, Schöll R, Semmler T, Woth K (2007) Future extreme events in European climate: an exploration of regional climate model projections. Clim Chang 81: $71-95$

Beranová R, Huth R (2008) Time variations of the effects of circulation variability modes on European temperature and precipitation in winter. Int J Climatol 28:139-158

Brier GW (1950) Verification of forecasts expressed in terms of probability. Mon Weather Rev 78:1-3

Cattiaux J, Douville H, Peings Y (2013) European temperatures in CMIP5: origins of present-day biases and future uncertainties. Clim Dyn. doi:10.1007/s00382-013-1731-y

Cheng X, Wallace JM (1993) Cluster analysis of the Northern hemisphere wintertime 500-hPa height field: spatial patterns. J Atmos Sci 50: 2674-2696

Christensen JH, Krishna Kumar K, Aldrian E, An S-I, Cavalcanti IFA, de Castro M, Dong W, Goswami P, Hall A, Kanyanga JK, Kitoh A,
Kossin J, Lau N-C, Renwick J, Stephenson DB, Xie S-P, Zhou T (2013) Climate phenomena and their relevance for future regional climate change. In: Stocker TF, Qin D, Plattner G-K, Tignor M, Allen SK, Boschung J, Nauels A, Xia Y, Bex V, Midgley PM (eds) Climate change 2013: the physical science basis. Contribution of Working Group I to the fifth assessment report of the Intergovernmental Panel on Climate Change. Cambridge University Press, Cambridge

Donat MG, Peterson TC, Brunet M, King AD, Almazroui M, Kolli RK, Boucherf D, Al-Mulla AY, Nour AY, Aly AA, Nada TAA, Semawi MM, Al Dashti HA, Salhab TG, El Fadli KI, Muftah MK, Dah Eida S, Badi W, Driouech F, El Rhaz K, Abubaker MJY, Ghulam AS, Erayah AS, Mansour MB, Alabdouli WO, Al Dhanhani JS, Al Shekaili MN (2014) Changes in extreme temperature and precipitation in the Arab region: long-term trends and variability related to ENSO and NAO. Int J Climatol 34:581-592

Dunn PK (2004) Occurrence and quantity of precipitation can be modelled simultaneously. Int J Climatol 24:1231-1239

Dunn PK (2008) Tweedie: Tweedie exponential family models. R package, R package version 1.5.1. Vienna, Austria

Friederichs P, Thorarinsdottir T (2012) Forecast verification for extreme value distributions with an application to probabilistic peak wind prediction. Environmetrics 23:579-594

Gao X, Pal JS, Giorgi F (2006) Projected changes in mean and extreme precipitation over the Mediterranean region from high resolution double nested RCM simulations. Geophys Res Lett 33, L03706

Giorgi F, Lionello P (2008) Climate change projections for the Mediterranean area. Global Planet Chang 63:90-104

Goubanova K, Li L (2007) Extremes in temperature and precipitation around the Mediterranean basin in an ensemble of future climate scenario simulations. Global Planet Chang 57:27-42

Hasan MM, Dunn PK (2011) Two Tweedie distributions that are nearoptimal for modelling monthly rainfall in Australia. Int J Climatol 31:1389-1397

Hasan MM, Dunn PK (2012) Understanding the effect of climatology on monthly rainfall amounts in Australia using Tweddie GLMs. Int J Climatol 32:1006-1017

Haylock MR, Hofstra N, Klein Tank AMG, Klok EJ, Jones PD, New M (2008) A European daily high-resolution gridded dataset of surface temperature and precipitation. J Geophys Res-Atmos 113, D20119. doi:10.1029/2008JD10201

Hertig E, Jacobeit J (2014) Variability of weather regimes in the North Atlantic-European area: past and future. Atmos Sci Lett. doi:10. $1002 /$ asl 2.505

Hertig E, Jacobeit J (2013) A novel approach to statistical downscaling considering nonstationarities: application to daily precipitation in the Mediterranean area. J Geophys Res Atmos 118:520-533

Hertig E, Seubert S, Paxian A, Vogt G, Paeth H, Jacobeit J (2013a) Changes of total versus extreme precipitation and dry periods until the end of the twenty-first century: statistical assessments for the Mediterranean area. Theor Appl Climatol 111:1-20

Hertig E, Seubert S, Paxian A, Vogt G, Paeth H, Jacobeit J (2013b) Statistical modeling of extreme precipitation for the Mediterranean area under future climate change. Int J Climatol. doi:10.1002/joc. 3751

Hertig E, Jacobeit J (2008) Assessments of Mediterranean precipitation changes for the 21 st century using statistical downscaling techniques. Int J Climatol 28:1025-1045

Hurrell J, Kushnir Y, Ottersen G, Visbeck M (eds) (2003) The North Atlantic Oscillation: climatic significance and environmental impact. Geophys. Monogr. Ser. 134, AGU, Washington, D.C.

Iglesias A, Garrote L, Flores F, Moneo M (2007) Challenges to manage the risk of water scarcity and climate change in the Mediterranean. Wat Res Manag 21:775-788

Jacob D, Petersen J, Eggert B, Alias A, Christensen O, Bouwer LM, Braun A, Colette A, Déqué M, Georgievski G, Georgopoulou E, 
Gobiet A, Menut L, Nikulin G, Haensler A, Hempelmann N, Jones C, Keuler K, Kovats S, Kröner N, Kotlarski S, Kriegsmann A, Martin E, Meijgaard E, Moseley C, Pfeifer S, Preuschmann S, Radermacher C, Radtke K, Rechid D, Rounsevell M, Samuelsson P, Somot S, Soussana J-F, Teichmann C, Valentini R, Vautard R, Weber B, Yiou P (2014) EURO-CORDEX: new high-resolution climate change projections for European impact research. Reg Environ Chang 14:563-578

Jacobeit J, Dünkeloh A, Hertig E (2007) Mediterranean rainfall changes and their causes. In: Lozan J et al (eds) Global change: enough water for all? Wissenschaftliche Auswertungen, Hamburg, pp 195-199

Kalnay E, Kanamitsu M, Kistler R, Collins W, Deaven D, Gandin L, Iredell M, Saha S, White G, Woollen J, Zhu Y, Chelliah M, Ebisuzaki W, Higgins W, Janowiak J, Mo KC, Ropelewski C, Wang J, Leetmaa A, Reynolds R, Jenne R, Joseph D (1996) The NCEP/NCAR 40-year reanalysis project. Bull Am Meteorol Soc 77:437-471

Kistler R, Kalnay E, Collins W, Saha S, White G, Woollen J, Chelliah M, Ebisuzaki W, Kanamitsu M, Kousky V, van den Dool H, Jenne R, Fiorino M (2001) The NCEP/NCAR 50-year reanalysis: monthly means CD-ROM and documentation. Bull Am Meteorol Soc 82:247268

Kyselý J, Beguería S, Beranová R, Gaál L, López-Moreno J (2012) Different patterns of climate change scenarios for short-term and multi-day precipitation extremes in the Mediterranean. Glob Planet Change 98-99:63-72

López-Moreno J, Vicente-Serrano SM, Morán-Tejeda E, Lorenzo-Lacruz J, Kenawy A, Benigston M (2011) Effects of the North Atlantic Oscillation (NAO) on combined temperature and precipitation winter modes in the Mediterranean mountains: observed relationships and projections for the 21st century. Glob Planet Chang 77:62-76

McCullagh P, Nelder JA (1989) Generalized linear models. Monographs on statistics and applied probability 37. Chapman \& Hall, London

Meehl GA, Covey C, Delworth T, Latif M, McAvaney B, Mitchell JFB, Stouffer RJ, Taylor KE (2007) The WCRP CMIP3 multi-model dataset: a new era in climate change research. Bull Am Meteorol Soc 88:1383-1394

Michelangeli PA, Vautard R, Legras B (1995) Weather regimes: recurrence and quasi stationarity. J Atmos Sci 52:1237-1256

Moore GWK, Renfrew IA, Pickart RS (2013) Multidecadal mobility of the North Atlantic Oscillation. J Clim 26:2453-2466

Philipp A, Della-Marta PM, Jacobeit J, Fereday DR, Jones PD, Moberg A, Wanner H (2007) Long term variability of daily North Atlantic-
European pressure patterns since 1850 classified by simulated annealing clustering. J Clim 20(16):4065-4095

Plaut G, Simonnet E (2001) Large-scale circulation classification, weather regimes, and local climate over France, the Alps and Western Europe. Clim Res 17:303-324

Preisendorfer RW (1988) Principal component analysis in meteorology and oceanography. Developments in atmospheric science 17. Elsevier, Amsterdam

Quadrelli R, Pavan V, Molteni F (2001) Wintertime variability of Mediterranean precipitation and its links with large-scale circulation anomalies. Clim Dyn 17:457-466

Raible CC, Lehner F, González-Rouco JF, Fernández-Donado L (2014) Changing correlation structures of the Northern Hemisphere atmospheric circulation from 1000 to 2100 AD. Clim Past 10:537-550

Tebaldi C, Hayhoe K, Arblaster J, Meehl G (2006) Going to the extremes: an intercomparison of model-simulated historical and future changes in extreme events. Clim Chang 79:185-211

Tramblay Y, El Adlouni S, Servat E (2013) Trends and variability in extreme precipitation indices over Maghreb countries. NHESS 13: 3235-3248

Ullmann A, Fontaine B, Roucou P (2014) Euro-Atlantic weather regimes and Mediterranean rainfall patterns: present-day variability and expected changes under CMIP5 projections. Int J Climatol 34:2634 2650

Van Vuuren DP, Edmonds J, Kainuma M, Riahi K, Thomson A, Hibbard K, Hurtt G, Kram T, Krey V, Lamarque J-F, Meinshausen M, Masui T, Nakicenovic N, Smith S, Rose S (2011) The representative concentration pathways: an overview. Climatic Change 109:5-31

Vautard R (1990) Multiple weather regimes over the North Atlantic: analysis of precursors and successors. Mon Weather Rev 18:2056 2081

Von Storch H, Zwiers FW (1999) Statistical analysis in climate research. Cambridge University Press, Cambridge, p 484

Wanner H et al (2001) North Atlantic Oscillation-concepts and studies. Surv Geophys 22:321-382

Ward J (1963) Hierarchical grouping to optimize an objective function. J Am Stat Assoc 58:236-244

Wilks DS (2006) Statistical methods in the atmospheric sciences. Elsevier, Amsterdam

Yiou P, Nogaj M (2004) Extreme climatic events and weather regimes over the North Atlantic: when and where? Geophys Res Lett 31, L07202 